UDK 785.02(497.4) "19"

Leon Stefanija

Filozofska fakulteta Univerze v Ljubljani

Philosophical Faculty, University of Ljubljana

\title{
Kompozicijske zasnove v slovenski instrumentalni glasbi zadnje četrtine 20. stoletja $^{1}$
}

\section{Compositional practice in Slovenian instrumental music of the last quarter of the $20^{\text {th }}$ century}

Ključne besede: slovenska glasba, instrumentalna glasba, glasba 20. stoletja

POVZETEK

Razglasitev postmodernosti za nekakšno uuravnavajočo idejo" sodobne kulture je - skupaj s prepričanjem o "nepreglednosti" umetniških hotenj ustoličila stališče, da je sodobni skladatelj neizogibno primoran $\mathrm{k}$ predrugačevanjem preteklih kompozicijskih praks. Razlog temu je dejstvo, da je ideologija Novega, tako značilna za glasbeno zapuščino 20. stoletja, izgubila nekdanjo ostrino. Zdi se, da ta domala nevprašljiva poteza sodobne skladateljske prakse temelji na podmeni o manku skupnega obzorja meril.

Problematika "postmoderne nepreglednosti je bolj priča družbene perpleksnosti kakor pa znamenje kompozicijskih značilnosti. Gre namreč za vprašanje miselne drže: kaže pojmovanje glasbene postmodernosti kot "tisočerih soobstoječih ogledal" razumeti kot nov, splošno uveljavljen zgodovinopisni korektiv ali kot begajoči konec nekoč domnevno homogenega razvoja kompozicijske
Key words: Slovene music, instrumental music, $20^{\text {th }}$ century music

\section{SUMMARY}

The proclamation of postmodernity as a kind of "regulative idea" of contemporary culture has along with the belief about the "Unübersichtlichkeit" of artistic volition - enthroned the notion that contemporary composers are compelled to modify the past compositional practices. The reason is the fact that the ideology of the New, so characteristic of $20^{\text {th }}$ century musical tradition, somehow lost its former sharpness. This almost unquestioned feature of contemporary compositional practice seems to be discussed on the assumption that there is no common horizon of criteria.

Nonetheless, the problematics of "postmodern Unübersichtlichkeit" appears more as a witness of the social perplexity than as a token of compositional characteristics. Namely, it remains an open question of a certain intellectual stance whether the notion of musical postmodernity as a "myriad 
preteklosti? Vendar to vprašanje presega okvir tega prispevka, osredotočenega na kompozicijski aparat. Zato bi želel pretresti utemeljenost omenjene podmene predvsem $z$ ozirom na simfonično glasbo, značilno za zadnji desetletji 20. stoletja na Slovenskem. of co-existing mirrors" should be seen as a new, widely accepted historiographical corrective, or as a baffling end of the once supposedly homogeneous unfoldment of the compositional past. But this question is beyond the scope of this paper, which focuses on the compositional apparatus. Thus, I would like to address the prospects of this assumption with regards above all to the symphonic music of the last two decades of the 20th century in Slovenia.

Mimo podrobnejše opredelitve pojma postmoderne, za katerega se zdijo še posebej značilne obravnave s poudarki na pojmovno-relacijskih, pojmovno-zgodovinskih, kritiškokulturoloških, ali pa znanstveno-spoznavnih vprašanjih, ${ }^{2}$ v sestavku obravnavam nekatere kompozicijske zasnove, značilne za slovensko resno muziko obdobja, ki se ga je oprijela oznaka postmoderna.

1 V izvirni obliki je bila študija predstavljena kot nastopno predavanje za izvolitev v naziv docenta muzikoloških znanosti na Oddelku za muzikologijo Filozofske fakultete Univerze v Ljubljani 18. 4. 2000.

2 Pojmovno-relacijski pretresi (npr. Hermann Danuser, Zur Kritik der musikalischen Postmoderne, v: Neue Zeitschrift für Musik 1988/12) so tesno povezani bodisi s pojmovno-zgodovinskimi bodisi z znanstveno-spoznavnimi vprašanji, značilnimi predvsem za literarno-teoretske, filozofske, kulturološke ali pa sociološke analize pojma. Zaradi prepletenosti omenjenih razsežnosti pojma je zato pri njegovi uporabi mogoče zaslediti navidez protislovne nezdružljive razlike, kot nakazuje naslednja primerjava navajanja pojma postmoderne pri Dragotinu Cvetku in Andreju Rijavcu.

Dragotin Cvetko, na primer, enači postmoderno s "postwebernjansko fazo" in obdobjem "eksperimenta" ter ob začetku osemdesetih let postavi domnevo, da je sodobna glasba [torej glasba postmoderne] 'brezstilna ali vsaj pluralistično prostrana, da predstavlja ne le vsak avtor, ampak celo vsako njegovo delo svoj, lasten stil ali način oblikovanja." (Dragotin Cvetko, Postmodernizem?, v: Sodobnost XXX/5, DZS Ljubljana, 478.)

Toda glede povednosti estetskega je Cvetkova časovna zamejitev postmoderne vprašljiva. Stališče Andreja Rijavca, "da je bil [Uroš] K[rek] vedno postmodernist (še pred nastopom postmoderne), "kljub provokativnosti namreč opozarja na semantično pojmovanje postmoderne v osemdesetih in devetdesetih letih. (Enciklopedija Slovenije, 6. zvezek, Ljubljana 1992, str. 6.) Obe umevanji postmoderne sta smiselni. Cvetkovo zato, ker pristopa s historiografskega stališča "glavnega toka", katerega je domnevno presegla ( $v$ ožjem smislu proklamirana ob koncu sedemdesetih let) filozofija "konca velikih zgodb" J.-F. Lyotarda, torej filozofija, sestavljena iz "vrste velikih" zgodb o malem, posebnem, marginalnem. Rijavčevo zato, ker opozarja na semantično prepletenost sodobnega $\mathrm{z}$ minulim in motri "brezstilnost" oziroma "pluralistično prostranost « $\mathrm{S}$ stališča estetske povednosti.

Omenjene ravni obravnave ločuje od sodobne dnevno-kritiške uporabe pojma postmoderne predvsem "želja po razumevanju“. Sicer tudi dnevno-kritiška uporaba pojma izhaja iz "želje po vzporejanju“ sedanjosti in preteklosti. V kritiških navajanjih pojma postmoderna je njegova vsebina predvsem priročno poenostavljena na obseg, primerljiv $z$ naslednjim. Leta 1995 je v 59. številki (junij, str. 64) revije za novo glasbo MusikTextepristala notica z odkrito ironičnim naslovom: Alles $p$. V

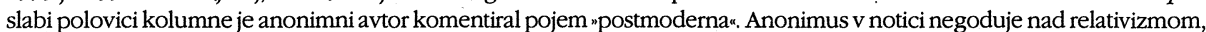
ki sprernlja pojem "postmoderna", in opozarja na njegov vsebinsko nejasen obseg. Tako je označil "Vokabel 'postmodern'" kot vseprisotno oznako, ki se pojavlja v slabih umetnostnih kritikah, ko pisec "gar nicht genau weiß, um was es sich eigentlich handelta.

Uredniku Ulrichu Dibeliusu, enemu vodilnih poznavalcev evropske glasbene sodobnosti, se je zdelo smiselno uvrstiti omenjeni Anonimusov komentar v strokovno revijo, čeprav (ali ravno zato, ker) je pred tem že izšel v rubriki "sovražna beseda tedna“ (Haßwort der Woche) v münchenskem Süddeutsche Zeitung. Notica nemara ne bi pritegnila pozornosti, v kolikor iz Anonimusovih očitkov ne bi bilo razvidno, da zgolj zastavlja vprašanja o merilih, ki so izrazito kritiška. ("Schreibt einer einen faden Siebenhundertseitenschinken in altertümlicher Manier, so ist er kein Langweiler, sondern ein ,Postmoderner'،. Ali pa dalje: „Überhaupt ist anscheinend alles p., was nahe den siebziger Jahren kam und nicht ausschaut wie irgendetwas aus den Jahrzehnten davor.") Prav zaradi kritiške ostije v končni fazi mogoče reči, da Anonimus očita "pu-ju, kar bi bilo mogoče očitati tudi njemu: vendar ne zato, ker bi zavajal s svojim negodovanjem nad plehkostjo v umetnosti, temveč spričo dejstva, da imponderabilijo, kakršna je "postmodernost“, kritizira z enakimi (ne istimi!) imponderabilijami, kakršni sta "plehkost" ali pa "reakcionarnost،. (Spomniti namreč kaže, da je Alma Mahler Werfel, avgusta leta 1899, po preigravanju klavirskega izvlečka prve simfonije svojega kasnejšega soproga, v svoj dnevnik zapisala: "ostudno-potpuri Wagnerjevih oper.. Mahler pravzaprav ni mogel doživeti bolj jedkega očitka plehkosti. Zlasti še, ker ga je izrekla oseba, za katero nexistiert nur, was morgen 


\section{MUZIKOLOŠKI ZBORNIK • MUSICOLOGICAL ANNUAL XXXVII}

Za slovensko glasbo bi bili časovna zamejitev in vsebinska opredelitev postmoderne vprašljivi glede na doslej opravljene raziskave. Uvodoma zato kaže ob Lebičevem videnju značilnosti skladateljskih prizadevanjv sedemdesetih letih 20 . stoletja, ${ }^{3} \mathrm{ki} \mathrm{se}-\mathrm{kot}$ večina preglednih "ugotovitev stanj» na področju kompozicijskih prizadevanj v obdobju proklamiranega konca avantgard - ${ }^{4}$ izteče $z$ mislijo o "padcu v veliko svobodo" in "sklenjenem krogu" modernizma, pripomniti, da soobstoja različnih avtorskih poskusov predrugačevanja kompozicijskih značilnosti iz preteklih obdobij in drugih glasbenih kultur ne kaže posplošeno časovno zamejevati. Časovna zamejitev je vezana na vsebinska vprašanja. In ne zdi se dvoumno, da se postmodernost v glasbi - navzlic različno razumljeni postmoderni: postmoderni kot "simulakru "brez izvirnika (J. Baudrillard), "Odmevu" nekoč (vsaj domnevno) zanesljivih podob, ali pa kot "zbirki lokacij", kjer se prepleta vrsta

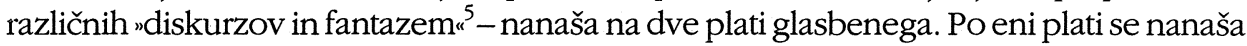
na različne bolj ali manj določljive ravni preobrazbe minulega v sedanjosti, medtem ko se po drugi plati pojem navezuje tako rekoč na bivanjsko ukoreninjenost glasbe, na "drobljenje" skladateljskih hotenj, ki prinašajo različne estetske rešitve in zahtevajo premislek o sočasnosti različnega, drugačnega, ne le preteklega. Tako prvo, kompozicijsko plat glasbenega stavka kot drugo, estetsko razsrediščenost glasbe bi bilo vprašljivo časovno in vsebinsko posploševati.

Iztočnico pričujočega razmisleka o značilnostih instrumentalnega glasbenega stavka v zadnji četrtini 20. stoletja na Slovenskem tako kaže opredeliti $z$ dvema vprašanjema. Mišljeni sta kot analitični iztočnici, ki bi jima izčrpna obravnava značilnosti slovenske glasbe s konca 20. stoletja nedvomno dodala vrsto drugih. Prvo vprašanje se glasi: kaj se v kompozicijskih postopkih kaže kot predrugačeno glede na preteklost? In drugo: katere estetske poteze kaže upoštevati pri obravnavi slovenske glasbe zadnje četrtine 20. stoletja?

wahr ist. Das von gestern überlasse ich dem Publikum und den Kritikern", kot je zapisala Alma Mahler v svoji biografiji; v izdaji Fischer Taschenbuch Verlag 1991, 63.) Zato kaže "priročno-kritiške navedbe pojma razumeti kot pomembne spoznavne iztočnice, ki jih upoštevajo pojmovno-relacijski, pojmovno-zgodovinski in znanstveno-spoznavni pretresi pojma postmoderna. Slednji je primerljiv $z$ drugimi "povzemajočimi slogovnimi in estetskimi približki (kot barok, klasicizem, romantika itn.), s katerimi si umetnostne vede pomagajo pri razkrivanju določenih kulturnih hotenj.

3 Lebič razmeji nasledje „tipe « skladateljskih prizadevanj, ki so značilni od sedemdesetih let 20 . stoletja dalje:

1) "[N] a ustvarjalce ali dela, ki so tudi sredi priostrenega modernizma ostali pri svojih izvornih odločitvah, največkrat s koreninami $v$ neoklasicizmu ali pa poznoromantični in postimpresionistični smeri.“"

2) „[N]a ustvarjalce ali dela, ki vztrajajo v polju moderne tako, da nadaljujejo zahtevnejšo 'darmstadtsko varianto' ali pa da dograjujejo enostavnejšo energetsko-ploskovno aleatorično smer."

3) "[N]a ustvarjalce ali dela, ki iz tihega nasprotovanja modernističnemu manierizmu najdejo zglede v ameriški pocageovski smeri."

4) "[N]a ustvarjalce ali dela, ki modernistični predstavni svet širijo - pluralizirajo - tako, da ga bogatijo z najrazličnejšimi elementi: s preteklim, mitološkim, folklornim [...], s palimpsestnim prekrivanjem arhetipskega z mlajšim in novim." (Lojze Lebič, Glasovi časov (IV), v: Naši zbori, 1994/3-4, letnik 47, Ljubljana, 60-61.)

4 Prim., na primer tri zbornike: Rudolf Frisius, ur., Neue Musik 1999: Bilanz und Perspektiven. Sieben Kongressbeiträge, Veröffentlichungen des Instituts für Neue Musik und Musikerziehung, Band 40, Darmstadt 2000; Otto Kolleritsch, ur., Wiederaneignung und Neubestimmung. Der Fall sPostmoderne "in der Musik, Studien zur Wertungsforschung, Band 26, Wien - Graz 1993; Wilfried Gruhn, ur., Das projekt Moderne und Postmoderne, Regensburg 1989.

5 Miško Šuvaković, Postmoderna (73 pojma), Beograd (Narodna knjiga/Alfa), 1995, 5. 


\section{Histori(ci)zem ${ }^{6}$}

Vrsta slovenskih skladateljev se pri komponiranju navezuje na posamezne zgodovinske kompozicijske predloge. Poudarjanje zgodovinskosti je treba seveda nekoliko natančneje opredeliti spričo pogosto izražanih stališč, da po izkušnji Cagea, vrste skrajno kompleksno dodelanih načinov strukturiranja glasbenega toka, elektroakustične, računalniške glasbe - torej po "izrabi zvočnega prostora" - nova kompozicijska izrazila niso mogoča. Ker bi natančna (glasboslovju nemara potrebna) tipologija sodobnih avtorskih predrugačenj zgodovinskih predlog močno presegla pričujoči razmislek, bi na tem mestu začrtal določen metodološki vzvod, ki razkriva nekatere, za glasbov zadnji četrtini 20. stoletja značilne estetske razsežnosti navezovanja na kompozicijsko preteklost.

Kot kompozicijska "idealna tipa", ki izpričujeta obseg in značilnosti skladateljskega histori(ci)zma, je mogoče jzbrati dve skladbi. Gre za Simfonietto in modo classico in due tempi Sama Vremška $(1988)^{7}$ in uspešnico Alda Kumarja z naslovom Post Art ali Glej, piše ti Wolfgang (1992).

Skladbi sta zasnovani na kompozicijskih vzorcih, značilnih za obdobje klasicizma. Glavna oblikovna razlika med skladbama je, da Vremškovo delo sledi načelu oblikovnega organicizma, medtem ko Kumarjev šeststavčni glasbeni akrostih Mozartu temelji na razgrinjanju posameznih harmonskih in melodičnih obrazcev klasicizma. Obe kompozicijski rešitvi - ali bolje: videnji klasicističnih značilnosti - torej zahtevata premislek o Cocteauojevi krilatici "nazaj k Mozartu".

Pred osemdesetimi leti je imelo Cocteaujevo ustvarjalsko geslo seveda drug pomen. Vendar njegova osnovna zamisel, namreč zamisel o "vrnitvi k resničnemu", ne le da do danes ni izgubila aktualnosti, temveč je za Vremškovo in Kumarjevo skladbo temeljna. Razlika je očitna v pojmovanju, v obzorju iskanja te "resničnosti“. Če je Vremšak svoj ustvarjalski pogled naravnal k izrazito avtorskemu preoblikovanju temeljnih kompozicijskih načel (novo)klasicizma, je Kumar umetniško moč poiskal v "potujevanju u izrazitih kompozicijskih postopkov iz njihovega izvirnega okolja. Vremšak torej gradi lastno glasbeno mišljenje na predrugačevanju kompozicijske celote, značilne za najbolj razširjeno glasbeno tradicijo Zahoda; nasprotno pa Kumarjevo načelo nizanja in preoblikovanja posameznih segmentov zastavlja vprašanje recepcijskega obzorja, ki sodi med osrednja za razumevanje glasbene prakse $v$ postmoderni. Ravno ta recepcijska sprememba zornega kota omogoča, da sicer isti, klasicistični kompozicijski podnet, lahkovodi k drugačni, ne odizvirne razlikujoči se estetski povednosti.

Oblikovnost Vremškove in Kumarjeve skladbe verjetno dovolj jasno nakazuje, da vprašanje zornega kota odpira prostor polemikam. Zakaj ne moremo Vremškove skladbe označiti kot primer glasbenega jezika, ki bi mu ustrezala oznaka "historični postmodernizem", temveč se zdi ustreznejši približek "novoklasicistični historizem"? In zakaj ni

6 Izraz "historicizem « sicer ni povsem primeren - zlasti zato, ker poudarja določeno razsežnost, vezano na pretekla obdobja -, toda vsebinsko ustreza kompozicijskim značilnostim glasbene logike, v kateri izstopajo posamezni odtržki bodisi preteklosti bodisi družbeno "tujerodnega" kot "znamenja", ki nakazujejo določeno semantično plat estetskega.

7 Podatke o navajanih skladbah je mogoče najti v Katalogu Edicij Društva slovenskih skladateljev (1994 oziroma na spletni strani: http://www.drustvo-dss.si/edicije.php3). 
dvoumno, da Kumarjev Post Art ponuja primer glasbenega mišljenja, kateremu bi oznaka "postmodernistični historicizem" ${ }^{8}$ bržkone ustrezala? Odgovor na prvo vprašanje ne bi smel biti dvoumen. Vremškovo glasbeno mišljenje sledi kompozicijskim načelom, ki so še posebej od druge polovice 18. stoletja dalje temelj glasbe Zahoda. Če bi jih želeli slogovno opredeliti, bi bilo potrebno nekoliko pretiravati o "novo-novoklasicizmu". Če bi se želeli izogniti slogovnim opredelitvam, bi morali seči po kritiškem oblikoslovnem besednjaku ("klenost celote", "jasna melodična dikcija", "ravnovesje ritmike in metrike" ipd.). Nasprotno pa se pri vprašanju o estetskih značilnostih Kumarjeve skladbe nekoliko zaplete. V prvi vrsti namreč ne gre za vprašanje razmerja med avtorskim preoblikovanjem celote, torej za vprašanje, "kako je skladba zgrajena glede na izhodiščno kompozicijsko tradicijo", temveč skladba zahteva pretres razmerja med fragmenti in njihovo estetsko povednostjo. Zastavlja torej recepcijska vprašanja (in ne kompozicijskopraktičnih). - Ali gre za "duhovito" zvočno skico ali "ironični" kolaž? Gre za svojevrsten "minimalizem" ali "nanizek razpoznavnih znamenj" kompozicijske tradicije, ki je brez pridevnika (Eggebrecht 1991) - klasična? Kumarjeva skladba namreč sodi med primere "postmodernistične" glasbene poetike, ${ }^{9}$ kakršno zagovarja Marko Mihevc. Z Mihevčevimi besedami, glasbena poetika postmoderne zahteva naslednje: „vplesti tudi lepoto, čustva, [...] zdravega eklekticizma, ki ni namenjen posnemanju preteklosti, ampak pomaga pri iskanju novih, da ne rečem prebavljivih smeri". ${ }^{10}$

Iz navedenih skladateljskih nazorov Marka Mihevca in Alda Kumarja je razvidno, da je ob avtorskem, izrazito histori(ci)stičnem predrugačevanju značilnosti kompozicijskih tradicij, za sodobnost pomembna še ena estetska smernica. Gre za zabrisovanje mejnic med nekoč bolj ali manj jasno razmejenimi glasbenimi besedišči ali eklekticizem.

Eklekticizem je verjetno ena najbolj pogosto navajanih, četudi vsebinsko širokih, težko opredeljivih značilnosti (ne le) glasbene "postmodernosti". Na Slovenskem je javno nemara najbolj odmevala ob izvedbi tretjega stavka (Haleluja) skladbe z naslovom In mentem venit mihi Marka Mihevca (1998). Poudariti je sicer treba, da je slogovni ekskurz v "kletzmer" tradicijo doslej izjema v opusu Marka Mihevca. Toda ekskurzi po različnih estetskih tradicijah v njegovem dosedanjem opusu niso izjeme, čeravno skladatelj v osnovi izhaja iz glasbenega mišljenja, ki je značilno za glasbeno moderno iz preloma $v$ 20. stoletje. Iz Mihevčevih partitur, med katerimi prevladujejo simfonične pesnitve, je razvidno, da skladatelj išče določene premene "glasbenopripovedne kode ", kakršno predstavlja Haleluja ali pa odsek „v tempu rumbe iz nekoliko starejše simfonične pesnitve z naslovom $V z$ namenju Bika.

8 Med historizmom in historicizmom obstaja v slovenskem jeziku sicer drobna, vendar ne zanemarljiva razlika: historizem se nanaša na poudarjanje določenega zgodovinskega sloga, medtem ko je historicizem stopnjevano, "pretirano poudarjanje" zgodovinskega. (Slovar slovenskega knjižnega jezika.)

9 Kumar vidi pomembno vlogo $\mathrm{v}$ "konkretnosti " kompozicijskih izrazil in meni, da je svet "klasične glasbe v kombinaciji $\mathrm{z}$ vsemi zvrstmi glasbe " danes "edina osnova za ustvarjanje nove glasbe“. (Kumar omenja, da se je v času sodelovanja z gostujočim poljskim gledališkim režiserjem Jerzyjem Grzegorzewskim leta 1986 "začel nagibati h 'konkretnosti' ', kar da je vplivalo tudi na "Čisto instrumentalno glasbo. (Pogovor s Cvetko Bevc, Kako upravičiti tišino, da stopimo v drug svet?, Slovenec 20.4.1995. Pogovor z Jelko Šutej Adamič, Glasba ni konstrukt, temveč čutenje, Delo 8.6.1998.)

10 Pogovor z Evo Šenčur, V resni glasbi ni dobrih naivcev, Sobotna priloga Dela 16.2.1999. „Razmišljal sem postmodernistično in združeval sodobne elemente $z$ elementi preteklih obdobij. [...] To je vendar smiselno, saj je skladba sestavljena iz več plasti." (Mihevc v obeh pogovorih zanika "romantiko", kar je nekoliko nenavadno, saj je ideja prepletanja starega z novim jedro romantične estetike enkratnega.) 
Podobno umetniško namero je zaslediti v vrsti drugih del. Omeniti kaže vsaj nekatera. Estetske značilnosti skladbe z naslovom In nomine Larise Vrhunc, na primer, zastavljajo vprašanje o "čutnem videzu ", ki se - tako kot pri zadnjem stavku cikla In mentem venit mihi Marka Mihevca - odtujuje, ali raje, potujuje estetske vrednote določenega glasbenega okolja in jih vpleta v drug skladateljski svet. Glavna estetska značilnost te ciklično zasnovane skladbe Larise Vrhunc je dobesedno igra prehajanja iz Haydnove kompozicijske prakse v skladateljičin zvočni okraj. Podobno, toda ne s historicističnim, temveč kompozicijsko-teoretičnim, vselej semantiziranim postopkom, t.i. "matričnim sozvočjem" - značilnim, na primer, za glasbo Aleksandra Skrjabina in, v drugi preobleki, tudi Olivierja Messiaena -, skladateljica razvija glasbeni tok v Koncertu za violino, klavir in orkester (1997). Kot priziv "drugega sveta" nastopi reminiscenca na dunajsko klasiko tudi v, recimo, Divertimentu Tomaža Sveteta, ki je nastal - tako kot In nomine Larise Vrhunc -v devetdesetih letih minulega stoletja. Kot svojevrsten poskus semantiziranja glasbenega stavka pa kaže omeniti še Dresdner Konzert Iva Petrića. V njem nastopijo tri teme. Skladatelj jih predstavi na notranji strani naslovnice. Med navedenimi temamidve sta izpeljani iz imen tonov oziroma po solmizaciji črk predvidenega mesta izvedbe in dirigenta, ena je protestantski koral - se "tema Dresden « izkaže za glavno motivično celico, iz katere izrašča glasbeni tok po načelu avtorskega predrugačevanja v osnovi klasičnih načel kontrapunkta. (Glasbeni antroponim namreč v skladbi nastopi kot miniaturna solistična kadenca v veznem taktu med drugim in tretjim stavkom. V nadaljevanju ga je sicer zaslediti kot uglasbitev dirigentovega imena ${ }^{11}$ in je morda vpleten tudi v kaki drugi obliki, primerljivi s sorodnimi poskusi v t.i. "partiturah za branje", vendar ni zaslediti njegove vplivnejše oblikotvorne vloge. Tako kot protestantskemu koralu, ki nastopi $v$ Toccati, t.154, in sklene skladbo, je z oblikovne plati tudi uglasbenemu poklonu dirigentu odmerjena simbol(ič)na vloga.)

Omenjene drobce iz simfoničnih opusov skladateljev, ki sooblikujejo slovensko glasbeno sodobnost, je mogoče šteti za skrajnice glasbenih dialogov s preteklostjo. Zanje je značilno, da so razpeti med avtorskim glasbenim mišljenjem in dvema vrstama kompozicijske logike. Prvo je mogoče označiti kot historistično, torej povezano z določeno zgodovinsko predlogo. (Vremškova Simfonietta.) Drugo pa je mogoče označiti kot historicistično, saj je zanjo značilno, da skuša "iztrgati", "potujiti", "rekontekstualizirati» ipd. posamezno glasbenokompozicijsko predlogo ali pa posamezno izrazito potezo preteklosti in ji podeliti določen(o) pomen(skost) v drug(ačn)em umetniškem okolju (kar je očitno zlasti ob Mihevčevi Haleluja).

Poudariti kaže to pomembno, za glasbeno sodobnost nemara temeljno razliko med glasbenima logikama, ki jima je mogoče slediti v oblikah glasbenega historizma Sama Vremška in historicizma Alda Kumarja ali Larise Vrhunc. Vremšak se očitno opira na sintaktična vodila glasbene logike, temeljne kompozicijske kategorije klasicističnoromantičnega (F. Blume) obdobja. Oblikovnost njegove skladbe temelji na tematičnem izpeljevanju. Nasprotno so "mozartovski" oblikotvorni obrazci v Kumarjevem Post Art odtržki posameznosti klasicističnega kompozicijskega besedišča, citat iz Haydnove simfo-

11 Toccata, vn.I.-II. v t.19-20. 
nije v skladbi Larise Vrhunc pa nedvoumen priklic minulega, nekakšen semantizirani vplet preteklosti v docela novo umetniško okolje: glasbeni navedek je člen igre razgrajevanja klasicističnega glasbenega toka, ki ponika v skladateljičin zvočni svet in se $z$ njim prepleta. Podobno je tudi Mihevčev žanrski priziv "kletzmer" godbe del semantiziranja sintakse, ki je "iztrgana" iz izvirnega okolja. Mihevčeva Halelujaje namreč primer ne le slogovnega, temveč nujno tudi sociološko zavzetega zvočnega "potujevanja", nekakšnega glasbenega "predružabljanja" določenega kompozicijskega uzusa.

Dosedanje izvajanje je mogoče strniti z ugotovitvijo, da je za vrsto sodobnih skladateljskih prizadevanj značilna določena histori(ci)stična poetika, pri kateri kaže ločevati med sintaktično-oblikovnimi predrugačenji določene kompozicijske tradicije (historizem) in različnimi namerami semantiziranja (historicizem).

\section{Transhistoricizem}

Za "čutni videz" glasbe, ki je nastala v zadnji četrtini 20. stoletja, je značilen še en način oblikovanja glasbenega toka. Ustreza mu oznaka estetski transhistoricizem. Kot ob pojmu "histori(ci)zem" se tudi ob izrazu "transhistoricizem" vsiljuje vrsta pomislekov spričo dejstva, da so nekateri opusi kljub časovni oddaljenosti nastanka ohranili estetsko svežino, ki se - za razliko od "hitrega zastarevanja nove glasbe" (T. W. Adorno) iz obdobja avantgard po drugi svetovni vojni-upira staranju. Naj zato poudarim, da transhistoricistične estetske povednosti ne gre enačiti s "prizivom nadčasnosti" estetskega, ki se v glasboslovni literaturi pogosto povezuje z idejo (relativno) "absolutne" Oziroma (relativno) "avtonomne" glasbe, kakršne primer je omenjena Vremškova Simfonietta. Nasprotno, kot transhistoricistično kaže označiti glasbeno mišljenje, katerega značilnosti so zvočni vzorci, ki se izmikajo vzporednicam z minulimi ali obstoječimi kompozicijskimi predlogami, čeprav bi jih mogli izslediti v "estetskem kapitalu" (N. Cook) Nove glasbe. Nakazuje ga denimo razgrajevanje klasicističnega glasbenega stavka v skladbi In nomine Larise Vrhunc, zlasti pa v njenem Koncertu za violino, klavir in orkester.

Transhistoricistično estetsko podobo v izčiščeni obliki razkriva opus Uroša Rojka. Njegova glasbena poetika je namreč recepcijsko nasprotje Mihevčevega in Kumarjevega "zdravega eklekticizma" ali Vremškovega "historicizma brez pridevnika". Kot primer transhistoricistične glasbene estetike je mogoče navesti glavne poteze dveh simfoničnih skladb Uroša Rojka. Prva nosi naslov Evokacija (1998), druga pa Sinfonia concertante (1992/1993).

Osrednja značilnost oblikovanja glasbenega toka skladbe Evokacija je fragmentarnost. Glasbeno besedišče skladbe tvorijo filigransko dodelane periode, iz katerih ni mogoče razbrati izrazitejše ciljne naravnanosti zvočnih dogodkov. Pomemben je proces oblikovanja, ne oblika celotne skladbe. Zato je mogoče reči, da Rojkov glasbeni stavek temelji na nekakšni "logiki pulverizacije“ akustičnega spektra, ki bi jo bilo vprašljivo zamejiti na določeno zgodovinsko predlogo, saj je značilna za nekatere skladatelje 20. stoletja, ki jim je sicer težko najti skupni imenovalec.

Zakaj je vprašljivo govoriti o določenem "skupnem zgodovinskem imenovalcu", bi na tem mestu lahko odgovorila primerjava Rojkovega glasbenega stavka s historicizmom 
Kumarjeve skladbe Post Art. Prva razlika med skladbama je ta, da v partituri Rojkove Evokacije pogoste prekinitve glasbenega toka jasno ločujejo posamezna zvočna sosredja; glasbeni tok Evokacijeje zasnovan na zaporedju detajliranih kaleidoskopskih zvočnih utrinkov. Nasprotno glasbeni proces Kumarjeve skladbe temelji na ponavljanju in modificiranju posameznih melodičnih in harmonskih zvez. Iz te kompozicijske značilnosti izhaja druga - glavna - razlika med histori(ci)stičnim in transhistoricističnim skladateljskim mišljenjem. Razlika med Rojkovo in Kumarjevo glasbeno logiko se v prvi vrsti nanaša na estetsko povednost glasbenega stavka - oblikovnost obeh del temelji na fragmentu in izmikanju organicistični celoti. "Krovni" semantični oblikoslovni določili, kot sta okrasek ali kadenca, sta smiselni le ob Kumarjevi skladbi. Nasprotno pa značilnosti glasbenega stavka Rojkove Evokacije zahtevajo analitični aparat, ki bi ustrezal svojevrstni fizikalistični poetiki, primerljivi, denimo, s poetikami Edgarja Vareseja, Gioacinta Scelsija ali Györga Ligetija. Ustrezati mora torej zvočni poetiki skladatelja, ki ga zanimajo - kot je Rojko poudaril na radijski okrogli mizi o Evokaciji-"raziskovanje zvoka", "ozaveščanje zvoka kot takega" in "estetika zvoka".

Treba je še dodati, da Rojkova "raziskovanja zvoka"kljub posameznim skupnim potezam niso identična s tistimi, ki jih je Gianmario Borio prikazal v svoji raziskavi avantgard iz šestdesetih let 20. stoletja. Tedanje značilnosti po Boriu namreč zaznamujejo prizadevanja po "Apellcharakter an die Lebenswelt". ${ }^{12}$ Nasprotno se Rojkova "Zvočna sosredja" tako rekoč izmikajo "življenjskemu svetu" v imaginarno, namišljeno zvočno krajino, ki je izrazito akustično-arhitektonska; apelira predvsem na poslušalčevo sposobnost vživljanja v igro zvočnih vzorcev, za katero bi težko našli semantizirane vzporednice, značilne za "apelirajoči značaj na življenjski svet", o katerem govori Borio. Ne zato, ker jih ne bi mogli najti, temveč zato, ker jih je več - ustrezno univerzalistični naravnanosti "iskanja glasbe v zvoku" - in so obenem "presplošne".

O nakazani oblikovnosti Rojkovega glasbenega mišljenja bi bilo vprašljivo reči, da skuša zanikati kompozicijsko izročilo Zahoda z nekakšno imaginativno, "a-semantično", izrazito fizikalistično glasbeno poetiko. Vez s preteklostjo je ena temeljnih razlik med "raziskovanji zvoka" avantgarde iz šestdesetih in Rojkovo akustično poetiko. To je, na primer, tudi pomembna razlika med glasbenima poetikama Uroša Rojka in Vinka Globokarja. Rojko redko (in tudi če, le za hip) prestopi prag glasbene "arhitektonike", najsi je mejnica med arhitektonskim in dekonstrukcijskim $\mathrm{v}$ nekaterih njegovih skladbah še tako priostrena. Nasprotno pa Globokarjeva glasba - prosvetiteljska igra akustično obstoječega in možnega - živi na tektonskih mejnicah različnih redov.

Doslej nemara najlepši primer Rojkove simfonične kompozicijske strogosti, ki črpa iz načel oblikovanja klasičnega glasbenega stavka, je videti v njegovem trojnem koncertu z naslovom Sinfonia concertante. Ta tristavčni ciklus izrašča iz enega glasbenega domisleka. Vsak stavek ga uvodoma predstavi v drugi preobleki, tako da osnova ostane nespremenjena. Značajska različnost stavkov je rezultat premen kompozicijskih prvin, na katerih temelji izhodiščni domislek. Zanj je v prvem stavku značilno intoniranjeoziroma artikulacijsko, akcentuacijsko in metrično nadrobno izoblikovano obkrožanjetonske višine.

12 Gianmario Borio, Musikalische Avantgarde um 1960. Entwurf einer Theorie der informellen Musik, Freiburger Beiträge zur Musikwissenschaft Band 1, Laaber Verlag, Laaber 1993, 173. 
Izhodiščni glasbeni domislek nastopi v drugem stavku v obliki melodične figure: gre za ritmično členjeno obkrožanje tonske višine. V tretjem stavku nastopi glasbeni domislek kot intonančno nihalov obliki oscilograma, ki ponazarja pospeševanje in upočasnjevanje ponovitev med tonoma oziroma kasneje med intervalskimi figurami (tremolo v časovnih enotah, večinoma med 7 in 12).

Za Rojkovo koncertantno simfonijo sta značilna nadrobno dodelano zvočno bogastvo in jasna ter učinkovito izpeljana kompozicijska zamisel. Oblikovna jasnost tako celote kot posameznih stavkov bi sodila med zglede učbeniških definicij organicističnih oblik. Vendar je kljub "tradicionalistični" oblikovni zasnovi očitno, da je vprašljiva vsakršna semantičnost estetskega, ki je nujni del glasbenih oblik. Partitura zahteva premislek o fizikalistični zamisli "čutnega videza": o nadrobnem fakturiranju glasbenega stavka kot dinamičnega pretoka tonskih višin, ki ga je mogoče opisovati z univerzalističnimi vzporednicami. Estetske poteze te skladbe bi morda kazalo nasloviti na načelna vprašanja o meji med umetniško-glasbenim in zvočno-konstruktivističnim. Toda glasbena izrazila Rojkove koncertantne simfonije nikakor ne zahtevajo tega vprašanja. Opredelitve estetskih izrazil skladbe se v končni fazi iztekajo v vprašanja o univerzalnih spoznavnih dvojicah, na primer, o razmerjih med "središčem" in "obrobjem", med "glavnim" in "stranskim", "kompleksnim" in "enostavnim", "izrazitim" in "prikritim" ali "umetniškim" ("arteficialnim") in "naravnim". Tovrstne opozicije so sestavni del zgodovine instrumentalne glasbe. In oblikovnost Rojkovega trojnega koncerta ne zapušča dvoma v pomen navedenih kognitivnih dvojic, temveč nasprotno, iz njih izhaja in jih tako rekoč tematizira kot lastno umetniško izhodišče, ne cilj (za razliko od Cagea ali tistih avantgardistov, ki jih je obravnaval Borio, delno pa tudi od Globokarja).

Kot zadnji zgled transhistoricistične estetske povednosti bi želel omeniti še nekatere značilnosti dveh skladb Lojzeta Lebiča, Queensland Music (1989) in Glasba za orkester Cantico I (1998). V njegovih stvaritvah so namrečv izredno dodelani obliki razvidne vse doslej omenjane estetske premise.

Po eni plati je razpoznavni znak Lebičeve novejše glasbe nadrobna fakturiranost posameznih oblikovnih členov celote. Skladatelj posveča posebno pozornost razmerju med celoto in njenimi odseki. Za razliko od omenjenih skladb Uroša Rojka - Lebiča privlačijo kontrasti, nasprotja, premene zvočnega duktusa. Lebičeva Queensland Music, kot je v spremni besedi k posnetku duhovito komentiral Peter Kušar, "odklanja kar vse oblikovne okvire 'musicae instrumentalis' [...]: pesemska oblika, variacija, rondo, fuga, sonata, so, če smem tako reči - pomembno odsotni." ${ }^{13}$ Celo priložnostni poročevalec nekdanjega časopisa Republika je decembra leta 1992 zapisal, da skladba nalikuje "hermetičnemu zvočnemu planetu". S sodbo o "hermetičnosti" Lebičeve glasbe se je seveda težko strinjati. Kljub temu pa je dovolj pomenljivo dejstvo, da je poročevalec, ki je Lebičevi Queensland Music očital, "da ničesar ne pove", razbral enovitost celotetudi sicer značilno potezo Lebičevih stvaritev - in v isti sapi dodal, da je zanjo značilna "subtilna spretnost, ki jo [skladatelj] z avtentičnim zanosom postavlja v ospredje» svoje stvaritve. Lebič je tudi sam poudaril: „Ostajam v mejah stroke. Ta pa me uči, da so vsa

13 Lojze Lebič, Queensland Music, Simfonija z orglami, Atelje III, DD 0144. 
pomembna glasbena dela - od Bachove umetnosti fuge do Bartókovih umetnij z zlatim rezom - grajena z velikim arhitektonskim premislekom, da so spoj nujnosti, da je zakone teh spojev mogoče analitično odkriti, tako kot so zavestno nastajali, da pa nam bodo za vedno ostali skriti vzgibi, ki so jih narekovali. ${ }^{14}$ Torej "niso temeljna vprašanja glasbe nasprotja med lepim in grdim, posvetnim ali religioznim .., " kar med drugim pravi Lebič, "marveč med resničnim in lažnim, urejenim ter neurejenim. ${ }^{15}$

Po drugi plati je za Lebičevo glasbeno govorico mimo dodelanih razmerij med deli in celoto značilno prefinjeno semantiziranje glasbenega stavka, ${ }^{16} \mathrm{ki}$ se razlikuje od fines Rojkovega "fizikalističnega raziskovanja zvoka". Lebič je svoje umetniške namere jasno povzel, ko je na primer poudaril, da išče "gramatikalnega občutka, ki bi glasbi vrnil nekaj izgubljene zmogljivosti govorice ${ }^{17}$.

Estetske značilnosti Lebičeve glasbe $v$ osnovi niso primerljive $\mathrm{z}$ zvočnimi kaleidoskopskimi podobami Rojkovega glasbenega stavka, niti z vzporednicami naplavin vsakdana in fascinacij nad naravnim, kot recimo pri Primožu Ramovšu, pa tudi ne gre za "brezinteresno" (novo)klasicistično estetiko kot pri Urošu Kreku; obstajajo, bolje, želijo živeti kvečjemu kot nekakšna duhovna anatomija zvoka. Pomembno je namreč, da Lebičevih oblikovnih rešitev ne enačimo z estetskim hermetizmom. Osebni "Svarilni glas" skladatelju namreč narekuje ravno nasprotno: "Če naj [moja glasba] poslušalca pritegne k iskanju globljih plasti in namigov, mora biti delo na površju razumljivo in prekrito z zadostnim številom razpoznavnih znamenj. ${ }^{18}$ Ne nazadnje je Lebič tudi opredelil kómponiranje kot "uokvirjanje, ko se kaj iz enega sveta znajde v drugem." " Tovrstni pretok estetskega po vsebinski plati resda dopušča, od poslušalca celo zahteva razkrivanje "globljih plasti", do katerih vodijo (tudi) "razpoznavna znamenja“. Vendar se v Lebičevi muziki te plasti izmikajo primežu imena oziroma so razpoznavna znamenja "namigi", "aluzije", "prizivi", "nakazovanja" ali pa "reminiscence" določenih pojavov. Najsi gre za "priziv" nečesa starožitnega, kot so na primer elementarni diastematski utrinki v Queensland Music, ali pa za (vsaj) štiri bolj ali manj očitno asociacijsko "prepustne " zvočne tvorbe v Glasbi za orkester: (1) bukoličnost melodike, (2) poudarjeni durovi razloženi sozvočji celeste (t. 187,

14 Pogovor z Milanom Deklevo, Kot da je svet že dopolnjen, Dnevnik 7.2.1994.

15 Družina 1. 47, 7. - 15. 2. 1998, 16. Kazalo bi nadalje vprašati, ali pojmovne dvojice, kakršne Lebič navaja, zahtevajo analitični pretres posameznih pojmovnih osi ali pa bi bilo potrebno poiskati ustrezno mrežo razmerij med njimi. Ne nazadnje je Lebič prepričan, da se bo težko odpovedal nasprotjemmed šumom in tonom, med odprto in zaprto obliko, med odrom in poslušalcem, med umetnostjo in vsakdanjostjo. (Lojze Lebič, Ustvarjalec ostaja svojemu otrošttu bližje ..., v: Lojze Lebič, Od blizu in daleč, ur. Jelena Ukmar Lebič, Kulturno društvo Mohorjan.) V njegovi glasbi udejanjeno prepričanje namreč zahteva pretres stopnje, po kateri se umetnost ločuje od vsakdanjosti, ton od šuma ali odrom in poslušalcem, in nadalje tudi pretres teh in podobnih nasprotij, ki nemara dovolj očitno tematizirajo vezi med glasbenim tkivom in semantičnimi recepcijskimi korelati, kar bi bilo vprašljivo zamejiti na opus posameznega skladatelja.

16 Komponiranje je za Lebiča "spoj zelo različnih nujnosti" (pogovor s Cvetko Bevc, Glasba je zveneča metafizika, Slovenec 11. 6. 1992), preobčutljiva entelehija, da bi bilo mogoče doseči soglasje o podobi estetskega mimo tega, da so skladbe "seizmograf duševnih stanj in razpoloženja (Jakob Jež, pogovor $z$ Vinkom Globokarjem in Lojzetom Lebičem ob njuni 60-letnici, Naši zbori 3-4/1994, 73). "Umetniška glasba, " nadaljuje Lebič, "mi pomeni zvočno izraženo človekovo inteligen$\mathrm{co}$, ki poleg graditeljske logike vključuje bogati svet čustev in navdiha. Samo tonsko gradivo in igra z njim mi je premalo. Potrebujem glasbeno idejo in usmerjeno duhovno razpoloženje." (Franc Križnar/Tihomir Pinter, Sto slovenskih skladateljev. Sodobni glasbeni ustvarjalci, Ljubljana 1997, 124.)

17 Pogovor z Milanom Deklevo, Kot da je svet že dopolnjen, Dnevnik 7. 2. 1994.

18 Prav tam.

19 Prav tam. 
ponovno v t. $200^{20}$ ), med katerima je (3) (v igri vl. solo, cl. b. in cl.; t. 196-198 ) slišati mahlerjanski "trenutek pripovedi, " ${ }^{21}$ in (4) "aluzija" na Bachovo znamenito kadenco iz Petega Brandenburškega koncerta v vlogi prehoda v tretji, zadnji del skladbe. Misel o določenem predrugačenju "kode glasbene naracije " ${ }^{22}$ je na vseh štirih mestih upravičena, četudi bi opustili navedene asocijacijske vzporednice (prvo literarnožanrsko, drugo kompozicijskoteoretično, tretjo in četrto avtorskopoetološko). Posameznim odsekom kot morebitnim simbolnim okruškom podeljuje semantično povednost in ne le sintaktični smisel predvsem širok razpon prepletanja in dodelovanja oblikotvornih prvin, ki ne sledi le akustični tonski igri, temveč tudi različnim, estetsko bogatim "duhovnim razpoloženjem". Vendar vsaki smiselni asociaciji, ki jo je mogoče razkriti v skladbi, ravno oblikovna dodelanost in enovita zasnova celote po načelu kontrasta podeli toliko vsebinskosti, kolikor jo odvzame. Z drugimi besedami: v oblikovnosti Glasbe za orkester je tovrstne "narativne" zvočne okruške sicer mogoče razumeti kot določeno glasbeno simboliko, toda zgolj v okviru igre prepletanja oblikotvornih prvin, v katere je vpeta domnev(a)na pripovednost. Za nedvoumno torej kaže šteti le, da vpetost aluzijsko prepustnih okruškov v oblikovno celoto po načelu soodvisnosti različnega sodi med osrednje značilnosti Lebičevega glasbenega stavka.

Naj strnem doslej omenjene značilnosti estetskega transhistoricizma. Za vrsto sodobnih skladateljskih prizadevanj je značilna glasbena poetika, pri kateri sicer kaže-kot pri histori(ci)stični estetski povednosti - razlikovati med sintaktično-oblikovno glasbeno logiko in semantiziranjem glasbenega toka, vendar se glasbena oblikovnost izmika določenim referenčnim analitičnim vzporednicam. Izrazje, ki se vsiljuje kot medij glasboslovne analize, nakazuje svojevrstno zvočno-fizikalistično oblikovnost glasbenega toka in zahteva premislek o univerzalizmu estetskega, za katerega je mogoče reči, da tvori recepcijski "diferencial" zgodovinske kompozicijsko-teoretične ideje (relativno) "avtonomne" oziroma (relativno) "absolutne" glasbe.

\section{Obraznost postmoderne}

Iz dosedanjega prereza estetskih vogelnikov sodobne slovenske glasbe je verjetno razvidno, katera so tista področja, ki so značilna za prizadevanja sodobnih slovenskih skladateljev. Na tej točki bom torej skušal odgovoriti na zastavljeni vprašanji o kompozicijskih predrugačenjih minulega in značilnih estetskih potezah $\mathrm{v}$ obdobju, ki se ga drži oznaka postmoderna.
MISELNI TOKOKROG O ESTETSKEM ZA SLOVENSKO INSTRUMENTALNO GLASBO ZADNJE CETRTINE 20. STOLETJA

\begin{tabular}{ll} 
& \multicolumn{1}{c}{$\begin{array}{c}\text { SINTAKTIČNO UMEVANJE } \\
\text { ESTETSKEGA }\end{array}$} \\
$\begin{array}{l}\text { HISTORICISTIČNO } \\
\text { POETOLOŠKO } \\
\text { IZHODIŠČE }\end{array}$ & $\begin{array}{l}\text { TRANSHISTORICISTIČNO } \\
\text { POETOLOŠKO } \\
\text { IZHODIŠČE }\end{array}$ \\
& \\
& SEMANTIČNO UMEVANJE \\
& ESTETSKEGA
\end{tabular}

20 V izogib napaki glede št. takta, ki ponekod predstavlja le orientacijski pripomoček označen s časovno enoto, navajam tudi stran v kopiji rokopisa izvirnika, ki ga hrani Društvo slovenskih skladateljev: 39, ponovno na str. 42 .

21 Caroline Abbate, Unsung Voices: Opera and Musical Narrative in the Nineteenth Century, Princeton UP 1991.

22 Prim. Robert Samuels: Mahler's Sixth Symphony. A Study in Musical Semiotics, Cambridge UP 1995, 133-165. 
$\mathrm{V}$ predrugačevanju minulega in obstoječega ponuja glasbena sodobnost pravcato množico obrazov. Vendar je kljub "novi nepreglednosti" posameznih skladateljskih estetik težko zanikati določeno tematično - nikakor vsebinsko - povezavo med njimi. Odgovor na prvo zastavljeno vprašanje ponuja naslednje ponazorilo, ki ga je mogoče označiti kot "miselni tokokrog o estetskem". V njem so soočene štiri doslej omenjane premise "Zvočnega videzaw: historicističnost-transhistoricističnost in semantičnost-sintaktični ustroj. Poudariti kaže, da sta skrajnici le medsebojno dopolnjujoča se pripomočka analize glasbenega stavka. V praksi je neizogibno govoriti le o pomikanju težišča med navedenimi, med seboj dopolnjujočimi se smernicami umevanja glasbenega stavka. Ne obstaja namreč ena sama historicistična estetika, temveč v zadnji četrtini 20. stoletja soobstajajo različne historicistične estetike. Vprašljivo pa bi bilo tudi govoriti o nesemantizirani sintaksi.

Kar "miselni tokokrog o estetskem" pove o slovenski skladateljski praksi zadnje četrtine 20. stoletja, kaže na tem mestu osvetliti v širšem zgodovinskem okolju glasbene tradicije 20. stoletja. Pogled na obdobje okoli prve svetovne vojne nekoliko bolj jasno nakazuje razloge za vprašljivost pojma "postmoderna" v glasbi. Za trenutek kaže spomniti na obdobje, ko se je v literaturi prvič pojavila publikacija z naslovom Nova glasba, od katere dalje se je zakoreninila navada pisanja pridevnika N/novo z veliko začetnico. Avtor je bil Paul Bekker, izšla pa je v začetku 20. let v Berlinu. Paul Bekker je o tedanji novi muziki zapisal, da zahteva "eine grundlegende psychische Erneuerung und Erweiterung unseres Musikempfindens “. ${ }^{23}$ Docela nasprotne zahteve je videl v N/novi glasbi Arnold Schönberg, katerega delo velja v glasbeni zavesti tako rekoč za paradigmo N/ nove glasbe, iz katere je izhajala vrsta povojnih avantgardistov. Schönberg je kategorično opredelil glasbeni novum svojega obdobja: "The only revolutionary in our time was [Richard] Strauss! ${ }^{24}$ Vendar ne Strauss glasbene moderne z bogatim kompozicijskim aparatom Elektreali pa simfonične pesnitve Don Quijote, temveč Strauss s slogovno preusmeritvijo v novoklasicizem. Iz Schönbergovega stališča je torej očitno, da je od novega pričakoval določeno "povedno smiselnost،. Nasprotno je Bekker povezoval glasbeni novum s čutnim, senzualističnim, domnevno nad-ali nepojmovnim. Torej z razsežnostmi, ki skušajo živeti mimo drugega od treh pojmov - inspiracije, racionalnosti in naključja -, ki jih je Hermann Danuser začrtal kot šibolete glasbenih poetik 20. stoletja.

Verjetno je razvidno, da je Bekkerjevo pojmovanje novega primerljivo $z$ Rojkovim, delno tudi z Lebičevim pojmovanjem estetskega. Schönbergovo pojmovanje novega pa je primerljivo - naj se sliši še tako protislovno - s prizadevanji tistih, ki iščejo glasbeni novum v avtorskem predrugačevanju "samoumevnih" kompozicijskih postopkov: torej tudi s tistimi, ki "postmodernizem" razumejo kot zabrisovanje meja med nekoč ostreje razmejenimi skladateljskimi mišljenji.

S pomočjo te razlike, na katero opozarja tudi omenjeni miselni tokokrog o estetskem, je mogoče razmejiti tri vodila oblikovanja glasbenega toka ali tri tipe estetik, značilnih za slovensko glasbeno sodobnost. Skorajda bi bilo odveč omeniti, da se v praksi pogosto

23 Paul Bekker, Neue Musik, Berlin 1919; nav, po Christoph von Blumröder, Neue Musik, v: Terminologie der Musik im 20. Jahrhunderts, ur. H.H. Eggebrecht, (Handwörterbuch der musikalischen Terminologie), Stuttgart 1995, $299-311$.

24 Arnold Schönberg, New Music, v: Style and Idea, nav. po izdaji Faber and Faber, ur. Leonard Stein, 137. 
prepletajo; vendar je mogoče tudi celotne opuse posameznih skladateljev razmeroma jasno prepoznati po naslednjih značilnostih.

Kot osrednjo značilnost prvega načina oblikovanja glasbenega toka ali tipa estetike kaže označiti načelo zasledovanja ideala avtonomije glasbene oblike. Pomembno je za skladbe oziroma skladatelje, ki sledijo bodisi določeni zgodovinski obliki bodisi posameznim kompozicijskim postopkom kot so razvijanje, variiranje ali izpeljevanje (na primer omenjeni skladbi Sama Vremška ali pa Iva Petrića) ${ }^{25}$. V obeh primerih gre za kakovostno, vselej avtorsko domišljeno «brušenje "delov klasične kompozicijske tradicije.

Osrednjo značilnost drugega načina oblikovanja glasbenega toka ali tipa estetike, pomembnega za skladbe oziroma skladatelje, ki ravno tako sledijo bodisi načelom določene zgodovinske oblike bodisi posameznim kompozicijskim postopkom, je videti v "dihotomiziranju" (ali "potujevanju“) zgodovinskih kompozicijskih danosti (na primer omenjeni skladbi Marka Mihevca ali Alda Kumarja $)^{26}$. Tu gre predvsem za poudarjeno kontrastiranje določenega "glasu preteklosti" v sicer avtorskem glasbenem mišljenju - in ne za "sintezo" avtorskega glasbenega mišljenja in oblikotvornih postopkov ter "obrazcev" preteklosti, kot pri prvem načinu oblikovanja glasbenega stavka.

Osrednja poteza tretjega načina oblikovanja glasbenega toka ali tipa estetike je pomembna za skladbe, katerih značilnosti se kljub posameznim sorodnostim izmikajo vzporejanjem z zgodovinskimi predlogami. Gre za načelo izmikanja zgodovinskim kompozicijskim vzporednicam $v$ imenu določene transhistoricistične estetske povednosti (na primer omenjeni Rojkovi in Lebičevi stvaritvi) ${ }^{27}$. Slednji kaže slediti s predočbo nekakšne "nastajajoče", ciljno nepredvidljive oblike, pri kateri je upravičeno iskati "narativne okruške", čeprav jih skladatelj morda ni namerno vpletel v stvaritev. Tovrstna domnevna semantizacija lahko nastopi tudi v različnih oblikah "čisto glasbene " figurativnosti, kot "gestičnost", v obliki glasbenih "aluzij" ali očitnejših "priklicov" določenega sloga, kompozicijske rešitve oziroma postopka ipd. Vvseh primerih je vprašljivo zamejiti estetske značilnosti na vzporednice z oblikami, izpričanimi v preteklosti, oziroma s "tujerodnimi" kompozicijskimi izrazili. Nasprotno, njihova dela zahtevajo premislek o glasbeni "strukturni semantiki" (A. J. Greimas): figurativni igri zvočnih vzorcev, ki jo je mogoče označiti kot svojevrstno "zvočnofizikalistično" poetiko ali glasbenoestetski "umišljeni univerzalizem", katerega vsebinske vzporednice so v drugem spoznavnem okolju razvijali teoretiki, ki jih je R. Schäfke v tridesetih letih 20. stoletja označil kot "energetike".

Navedeni izsledki tako dopuščajo izpostaviti poetološko in estetsko premiso. Iz obeh izrašča vrsta inačic, značilnih za postmoderno. Za poetološko premiso je značilno bodisi vprašanje o razmerju med zgodovinsko kompozicijsko predlogo in skladateljevim predrugačevanjem nekaterih njenih kompozicijskih značilnosti bodisi, vprašanje o

25. Ta način oblikovanja glasbenega toka je značilen še za nekatera dela iz opusov: Alojza Ajdiča, Nenada Firšta, Marjana Gabrijelčiča, Janija Goloba, Janeza Gregorca, Petra Kovača, Uroša Kreka, Aleksandra Lajovca, Marijana Lipovška, Pavla Mihelčiča, novejša dela Iva Petrića, Ljuba Rančigaja, Alojza Srebotnjaka, deloma Petra Šavlija, Pavla Šivica, Daneta Škerla ali pa Sama Vremška.

26 Na primer nekatera dela: Alojza Ajdiča, Brine Jež-Brezavšček, Alda Kumarja, Marka Mihevca, Maksa Strmčnika ali pa Larise Vrhunc.

27 Skladatelji, katerih nekatera dela je mogoče povezati s to predočbo, so Darijan Božič, Vinko Globokar, JakobJež, Lojze Lebič, Janez Matičič, Primož Ramovš, Uroš Rojko, Milan Stibilj, Tomaž Svete, deloma Peter Šavli, Igor Štuhec, Bor Turel ali pa Larisa Vrhunc. 
transhistoricističnostiali anti-zgodovinskosti zvočnega snovanja. Estetska premisa pa se nanaša na vprašanje o semantičnosti glasbenega stavka, ki živi mimo skrajnosti glasbenih avantgard, postavljen pred vprašanja o smislu in estetski povednosti. Ravno opustitev skrajnosti je namreč mogoče šteti za osrednji novum glasbene sodobnosti v primerjavi $z$ glasbenimi estetikami ter poetikami obeh avantgardnih gibanj 20. stoletja oziroma slovenskih skladateljev N/nove glasbe šestdesetih let, ko je ravno odstopanje v smeri ene ali druge plati glasbenega zagotavljalo drugačnost in - novost. Zdi se, da je postmoderna prinesla dvom $v$ "testing of the limits of aesthetic construction " ${ }^{28}$. Vendar obenem kaže, da je ide(ologi)ja novega, s katero so skladatelji upravičevali svoja umetniška "sporočila v steklenici", le zamenjala naslovnika. Ostala je nepogrešljiva, toda ne za skladatelja. Skladatelj v zasičenosti z obstoječimi "sporočili iz steklenice" ne preizprašuje toliko kompozicijskih slepih ulic preteklosti kolikor celostne miselne drže, ki je glasbo Zahoda vodila v "pustolovščino estetske avtonomije" (S. Kunze). Pač pa je ide(ologi)ja novega postala nepogrešljiva v ekonomiji kulture (tudi glasbene), za katero se zdi, da pomaga bledeti tudi nekoč ostremu in v osnovi tako rekoč izrazito kulturno-neekonomskemu "apelacijskemu značaju" estetik avantgardistov iz šestdesetih let, ki jih je prikazal G. Borio.

Sklep prereza značilnosti sodobne slovenske simfonične glasbe v okviru vprašanja glasbeno novega kaže tako strniti s pripombo o domnevni nepreglednosti estetskih obrazov. Vprašanje novega bi kazalo nadaljevati z izhodiščem v spoznavni zadregi, ki je nastopila s proklamacijo "postmoderne razsrediščenosti", in ki bi nemara morala izhajati iz Shakespearjeve misli "that which we call a rose / By any other name would smell as sweet ${ }^{29}{ }^{29}$ Zdi se namreč, da proklamacija postmoderne kot sestopa novega $\mathrm{v}$ "novo nepreglednost“ skuša preosvetliti prispodobo novega kot palčka na ramenih velikana, ki jo pripisujejo Bernardu iz Chartresa. Skuša jo preosvetliti kot trnjasto pot, na kateri je domnevno mogoče videti le velikane, ki zaradi izgube ravnovesja zadevajo drug ob drugega. Palčkom na njihovih ramenih se medtem pogled ne obrača le naprej, temveč je prisiljen premerjati okolico in pot pod sabo - torej izbrana kompozicijska in miselna vozlišča, po katerih stopajo njihovi velikani. (Zato so rekurzi na pojem postmoderne neizbežni in potrebni. V končni fazi je stališče "pluralizma glasbenih tradicij" eno osrednjih vprašanj sodobnega glasbenega zgodovinopisja.)

„Postmodernistična" preosvetlitev Bernardove prispodobe tako naslavlja vprašanje o hitrem zastarevanju novega (T. W. Adorno), ki je bilo osrednje za povojne avantgarde in je s proklamacijo postmoderne le pridobilo vrsto konotacij, tudi na druga kompozicijska področja. Zlasti pa odpira vprašanje o drugih spoznavnih merilih mimo tistih, na katerih

28 Daniel Albright, Untwisting the serpent: modernism in music, literature, and other arts, The University of Chicago Press, London $2000,29$.

29 "Romeo in Julija, 2. scena 2. dejanja, Julija: "Tis but thy name that is my enemy; Thou art thyself, though not a Montague. What's Montague? it is nor hand, nor foot, Nor arm, nor face, nor any other part Belonging to a man. $\mathrm{O}$, be some other name! What's in a name? that which we call a rose By any other name would smell as sweet*. 
je oprta pričujoča razprava. Še posebej pomembna se zdijo področja recepcije glasbe (kjer bi nemara kazalo naravnati razmislek k vrstam psihičnih pojavov), socialne psihologije (zlasti empiričnega raziskovanja poslušalskih navad), groysovske "kulturne ekonomije" (mehanizmov v kulturi) in $z$ njo povezanega "problema mase (razmerja med vlogami glasbe in vlogami drugih umetnosti na različnih ravneh človekovega delovanja). Čeprav se jih predstavljena problematika le obstransko dotika ali jih samo nakaže, nikakor niso manj pomembna za razumevanje (nemara ne le) sodobne slovenske glasbe. 